\title{
Characterization of Bioactive and Antioxidant Composition of Mountain Tea (Sideritis montana ssp. montana): Microwave-Assisted Technology
}

\author{
Emel Akbaba $(\mathbb{D} 1, *$
}

${ }^{1}$ Department of Biology, Faculty of Science, Firat University, Elazig, Turkey

\begin{abstract}
The use of synthetic antioxidants has been restricted and even prohibited in some countries due to their toxic effects. This study aims to perform the biochemical assays representing the bioactive compounds in Sideritis montana L. ssp. montana L. known as mountain tea. The study specifically investigates the potential application of mountain tea in the food industry as a natural antioxidant. Different extraction procedures using various solvents are carried out to obtain phenolic compounds and antioxidant activities in plant matrices. In this study, the maceration method was used for the extraction procedure. Furthermore, the microwave-assisted extraction method was applied to shorten the extraction time and decrease the solvent quantity. Methanol was used as a solvent in both conventional and microwave-assisted extraction procedures. The samples were evaluated in terms of the total phenolic compounds, total flavonoids, antioxidant activities, and metal chelating capacity. The obtained results for classical extraction and microwaveassisted extraction methods were found to be 51 and $55 \mathrm{mg} / \mathrm{g}$ for TPC, 16.3 and $22 \mathrm{mg} / \mathrm{g}$ for TFC, 93 and $103 \mathrm{mg} / \mathrm{g}$ for FRAP, and 284 and $282 \mathrm{mg} / \mathrm{g}$ for $\mathrm{MCC}$, respectively. The microwave-assisted extraction method produced higher concentrations of bioactive molecules as compared to the classical method. Microwave-assisted extraction was found to be superior to the conventional method in terms of effectiveness, extraction time, and solvent quantity. Besides, Sideritis montana ssp. montana is suggested in the food industry as a natural antioxidant instead of synthetic ones to prevent healthdamaging effects.
\end{abstract}

\section{INTRODUCTION}

Numerous studies have shown a high correlation between the consumption of medicinal plants in the prevention and treatment of various health problems including cancer, cardiovascular and neurodegenerative diseases. Phenolic compounds in medicinal plants and foods are known to significantly decrease the adverse effects of chemically reactive species on normal physiological functions in humans. The genus Sideritis L. (Labiatae/ Lamiaceae) comprises more than 150 species and several taxa are distributed in Turkey and other Mediterranean countries (Bilginoğlu, 2017). Many species that belong to Sideritis are traditionally applied to

\footnotetext{
${ }^{*}$ CONTACT: Emel Akbaba $\bigotimes$ eakbaba@firat.edu.tr University, Elazig, Turkey

Department of Biology, Faculty of Science, Firat
} 
prepare herbal teas (Semiz \& Özel, 2017), commonly known as "Mountain tea", which is widely consumed around the world due to its therapeutic properties. Many biological effects including anxiolytic, diuretic, antimicrobial, antibacterial, antioxidant, and anti-inflammatory effects of Sideritis species have been reported (Irakli et al., 2018) (Ognyanov et al., 2021). Sideritis species have a pleasant aroma making their consumption appealing to be consumed as herbal tea (Zyzelewicz et al., 2020). Also, many species of Sideritis have been shown to induce neuroprotective and memory-enhancing properties (Axiotis et al., 2020).

The physiological roles of phenolic compounds include their protection against disorders associated with oxidative stress such as cancer, atherosclerosis, cardiovascular, and neurodegenerative diseases. Regulating the endogenous antioxidant defense system, polyphenolic compounds participate as the scavengers of free radicals (Arruda et al., 2020). Antioxidants could be either natural or synthetic. Synthetic antioxidants have phenolic arrangements of many degrees of alkyl replacement, while natural antioxidants can be phenolic compounds including a- tocopherols, flavonoids, and phenolic acids, b- nitrogen compounds such as alkaloids, chlorophyll derivatives, amino acids, and amines, and c-carotenoids as well as ascorbic acid (Xu et al, 2021). Synthetic antioxidants such as butylated hydroxyanisole (BHA), butylated hydroxytoluene, propyl gallate, and tert-butylhydroquinone (TBHQ) have been used in the food industry attributable to their low cost and tasteless flavor. Synthetic preservatives are applied to the foods to prevent them from oxidants during processing, packaging, transportation, and storage. However, long-term excessive intake of the chemical residues of such synthetic preservatives has been reported to induce toxicity even carcinogenicity (Martelli \& Giacomini, 2018). Therefore, some countries such as China, Japan, Canada, and Europe have been restricted and even prohibited the use of synthetic antioxidants. Recently, BHA has been removed from the generally recognized as safe (GRAS) list of compounds. Natural products are considered safe alternatives to synthetic ones with many beneficial properties. Increasing reports on "green" preservation reagents called food-grade antioxidants are based on natural substances. Besides, phenolic compounds have also been shown to possess significant antibacterial activity (Ceylan et al., 2020). Therefore, application of natural antioxidants instead of synthetic ones could be a good candidate in food industry (Rodrigues et al., 2020).

Replacement of Sideritis-based antioxidants such as chlorogenic acid, quercetin, naringin, verbascoside, luteolin, and apigenin derivatives reported to be responsible for the antioxidant, anti-inflammatory, and anticarcinogenic effects with synthetic antioxidants may be suggested. Thus, Sideritis species could also be a good candidate in food industry instead of synthetic preservatives including TBHQ and the aforementioned ones (González-Burgos et al., 2011). Other possible applications of Sideritis for their higher phenolic profiles, range from food preservatives to cosmetics and also a product of interest for the pharmaceutical industry (Marchev et al., 2021). Due to its terpenoid constituents, Sideritis species could also be a good candidate as flavoring agents in the food industry (González-Burgos et al., 2011). The whole bioactive molecules of Sideritis may have synergistic effects with many other health-benefit properties.

Various plant extraction techniques could be divided into two main groups; namely, conventional and novel techniques. Conventional or classical extraction method includes maceration, Soxhlet, soaking, turbo-fast blending, and solvent permeation. On the other hand, the novel or so-called modern extraction processes include ultrasonic-assisted, subcritical, supercritical $\mathrm{CO} 2$, pressure-assisted, enzyme-assisted, and microwave-assisted extraction (MAE) methods. The conventional methods have great disadvantages due to their long extraction time and high solvent requirement. Therefore, a reliable, easy, quick, and ecofriendly plant extraction technique is significantly important to determine phenolic compounds and antioxidant activities (Chemat et al., 2009). 
In this study, total phenolic content (TPC), total flavonoid content (TFC), ferric reducing antioxidant power (FRAP), and metal chelation capacity (MCC) of Sideritis montana L. ssp. montana L. were determined. These parameters were suggested to be related to the food preservative as well as their contribution to health benefits. Their measurements were carried out using both conventional and MAE methods with a purpose to develop an alternative method taking into consideration less time and solvent-consuming procedure together with high efficiency.

\section{MATERIAL and METHODS}

\subsection{Chemicals and Materials}

Aluminum chloride, sodium acetate, potassium ferricyanide, iron (III) chloride, 1,10phenanthroline monohydrate, potassium hydrogen phosphate, sodium hydroxide, sodium carbonate, hydrogen phosphate, trichloroacetic acid, iron sulfate monohydrate, and FolinCiocalteu's phenol reagent used in this study were purchased from Merck (Germany). Quercetin, gallic acid, and $n$-hexane were purchased from Sigma-Aldrich (Germany), Iso Lab (Eschau, Germany), and Carlo Erba (Sabadell, Spain), respectively. A rotary evaporator (Buchi, Rotavapor R-100) coupled with a heating bath (B-100) and vacuum bath (V-100) was used to evaporate solvent for sample preparations; a microwave oven (Mars Express) was used for the extraction. UV Spectroscopy measurements were performed with UV-VIS (Isolab, Germany) spectrophotometer.

\subsection{Plant material}

Sideritis montana ssp. montana samples (as whole aerial parts) were purchased in 2020 from a local producer in Elazig and identified and confirmed. The leaves of the plant samples were removed and air-dried in a shady room at room temperature, and grounded in a high-speed household blender.

\subsection{Conventional solid/liquid extraction under stirring (Maceration)}

Plant samples $(10 \mathrm{~g})$ were placed in a balloon with $75 \mathrm{ml}$ methanol. At room temperature, the balloon was continuously stirred by a magnetic stirrer for 24 hours. Then the samples were filtrated by Whatman filter paper (102 Medium, $125 \mathrm{~mm}$, S-H Labware). This procedure was repeated 3 times. Finally, all extracts were combined and evaporated via a rotary evaporator at $40^{\circ} \mathrm{C}$ under the pressure of 150 mbar. After the evaporation, the extract was defatted by hexane. Then, the extract was first air-dried and completely dried in a vacuum oven (Nuve 180). From the extract, $0.1 \mathrm{~g}$ was dissolved in $8 \mathrm{~mL}$ methanol and used for the biochemical assays.

\subsection{Microwave-assisted extraction}

MAE was performed using a closed vessel microwave apparatus. The dried sample $(0.1 \mathrm{~g})$ was placed into polytetrafluoroethylene vessel of $70 \mathrm{~mL}$ and was extracted under different conditions with $8 \mathrm{~mL}$ of solvent ( $70 \%$ methanol in water). The temperature of the system was set as $60^{\circ} \mathrm{C}, 70^{\circ} \mathrm{C}$, and $85^{\circ} \mathrm{C}$. Three microwave powers were used $(200,300$, and $400 \mathrm{~W})$. The ramp time was adjusted to 10 minutes; the hold time was as 8, 14, and 20 minutes. The extraction conditions of MAE are described in Table 1. After the extraction, the vessels were allowed to cool, and then they were centrifuged at $3000 \mathrm{rpm}$ for 10 minutes. The supernatant was taken for biochemical analyzes. All procedures belonging to biochemical assays are given in Figure 1.

\subsection{Determination of Total Phenolic Content}

The Folin-Ciocalteu assay was used for the determination of the total phenolic content (TPC) in this study. The mechanism of this assay is based on the reduction of the Folin-Ciocalteu reagent by phenolic compounds (Magalhaes et al., 2008). The procedure of the total phenolic 
content assay is given in Figure 1a. Briefly, $0.5 \mathrm{~mL}$ sample or standard solutions (gallic acid) were

Table 1. The applied conditions of the microwave-assisted extraction method.

\begin{tabular}{cccc}
\hline $\begin{array}{c}\text { Temperature } \\
\left({ }^{\circ} \mathrm{C}\right)\end{array}$ & \multicolumn{3}{c}{$\begin{array}{c}\text { Time } \\
(\text { minutes })\end{array}$} \\
\hline 60 & 8 & 14 & 20 \\
70 & 8 & 14 & 20 \\
85 & 8 & 14 & 20 \\
\hline
\end{tabular}

Figure 1. The experimental procedures of a. total phenolic content, b. total flavonoid content, c. ferric reducing antioxidant power, $d$. metal-chelating capacity assays.

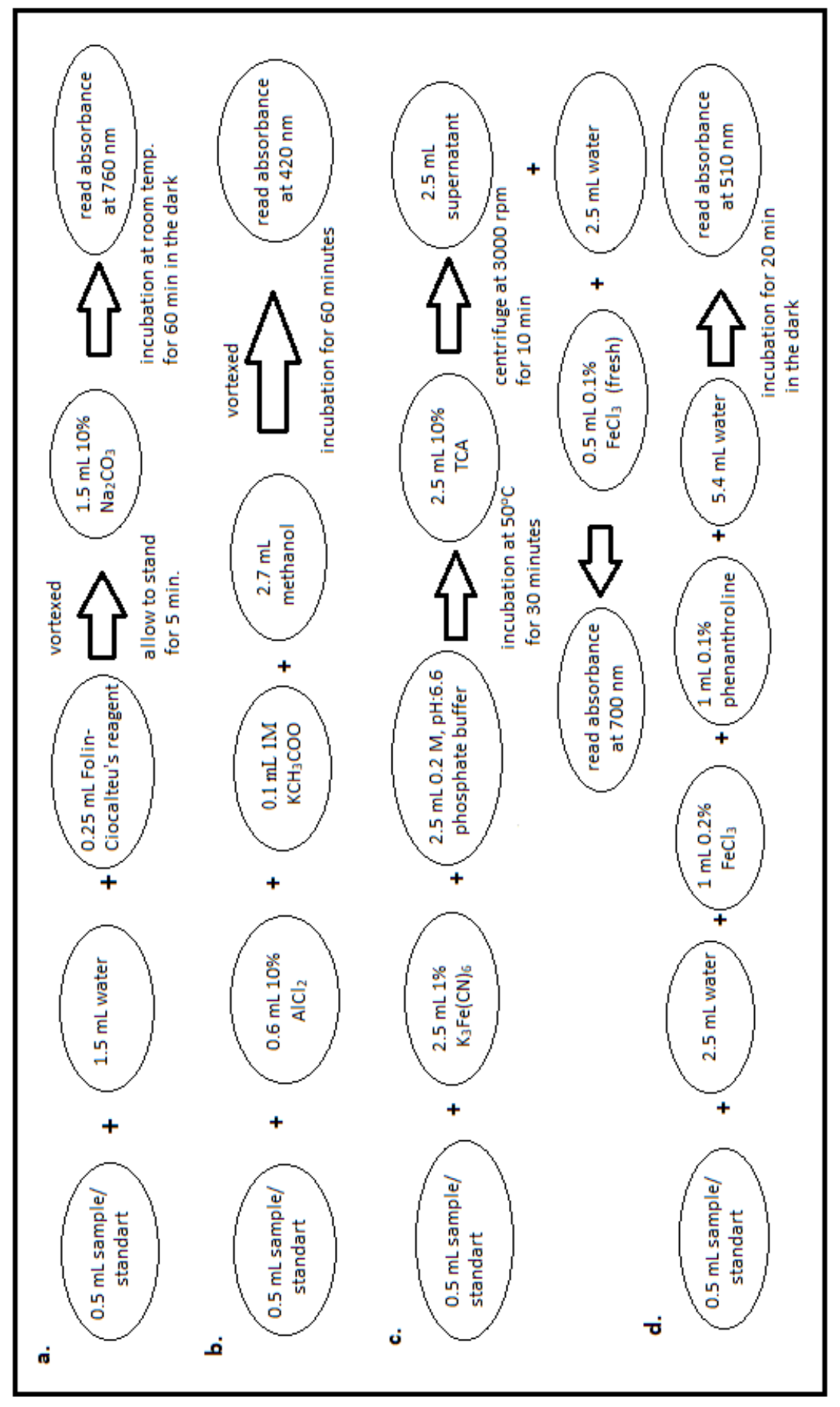


placed in test tubes with $1.5 \mathrm{~mL}$ water and $0.25 \mathrm{~mL}$ Folin-Ciocalteu reagent. After vortexing, the tubes were allowed to stand for 5 minutes. Then, $1.5 \mathrm{~mL} 10 \% \mathrm{Na}_{2} \mathrm{CO}_{3}$ was added prior to the incubation at room temperature in the dark for 1 hour. The absorbances of all samples were measured at $760 \mathrm{~nm}$ using a UV-Vis Spectrophotometer. The construction of the calibration curve $(5,10,20,50,100$, and $200 \mathrm{ppm})$ was obtained with gallic acid. The results are expressed as gallic acid equivalents/ the dry plant (mg GAE/gdw).

\subsection{Determination of Total Flavonoid Content}

The total flavonoid content was determined according to the aluminum chloride-colorimetric method. $0.5 \mathrm{~mL}$ sample or standard solutions (quercetin) were added in test tubes. $0.6 \mathrm{~mL} \mathrm{10 \%}$ $\mathrm{AlCl}_{2}, 0.1 \mathrm{~mL} 1 \mathrm{M} \mathrm{KCH}_{3} \mathrm{COO}$ and $2.7 \mathrm{~mL}$ methanol were added followed by the incubation for 1 hour (Figure $1 \mathrm{~b}$ ). The construction of a calibration curve $(5,10,20,50,100$, and $200 \mathrm{ppm})$ was obtained with quercetin. The absorbances were measured at $420 \mathrm{~nm}$. The results are expressed as quercetin equivalents/ the dry plant (mg QE/gdw).

\subsection{Ferric Reducing Antioxidant Power Assay}

Reducing power (FRAP) of the methanolic Sideritis montana extracts was determined based on their antioxidant principles to form a colored complex with potassium ferricyanide (Berker et al., 2010). $0.5 \mathrm{~mL}$ sample or standard solutions (quercetin) were added in test tubes with 2.5 $\mathrm{mL} 1 \% \mathrm{~K}_{3} \mathrm{Fe}(\mathrm{CN})_{6}$ and $2.5 \mathrm{~mL} 0.2 \mathrm{M}$ phosphate buffer (pH: 6.6). After the incubation for 30 min. at $50^{\circ} \mathrm{C}, 2.5 \mathrm{~mL} 10 \%$ TCA was included into the tube followed by the centrifuge for 10 min at $3000 \mathrm{rpm}$. Then $2.5 \mathrm{~mL}$ supernatant was pipetted into a new tube with $2.5 \mathrm{~mL}$ water and $0.5 \mathrm{~mL} 0.1 \%$ freshly prepared $\mathrm{FeCl}_{3}$ (Figure 1c). The calibration curve was obtained by using different quercetin concentrations between 5-200 ppm. The absorbances were measured at 700 $\mathrm{nm}$. The results are expressed as quercetin equivalents/ dry plant (mg QE/gdw).

\subsection{Metal Chelating Capacity}

Metal chelating activity of Sideritis was carried out using the 1,10-phenanthroline method. 0.5 $\mathrm{mL}$ sample or standard solutions (iron II sulfate) were added in test tubes. Then, $2.5 \mathrm{~mL}$ water, $1 \mathrm{~mL} 0.2 \% \mathrm{FeCl}_{3}, 1 \mathrm{~mL} 0.1 \%$ phenanthroline and $5.4 \mathrm{~mL}$ water were added. After vortexing thoroughly, the tubes were incubated for $20 \mathrm{~min}$ in the dark (Figure 1d). The results are expressed as iron II sulfate equivalents on the dry plant basis (mg Fe2+/gdw). The calibration curve was obtained by using different $\mathrm{Fe}^{2+}$ concentrations between $50-800 \mathrm{ppm}$. The absorbance was measured at $510 \mathrm{~nm}$.

\subsection{Statistical Analyzes}

All tests were conducted in triplicate. The mean \pm standard deviation was determined according to the results of each test. These results were statistically compared with One-way ANOVA and Tukey's post hoc test for multiple comparisons. $p<0.05$ was considered as the significance value.

\section{RESULTS and DISCUSSION}

Phenolic compounds, as potent antioxidants and have been known to induce many health benefits against degenerative diseases. Typically, a phenolic compound carries one or more hydroxyl groups on an aromatic ring. Phenolic compounds can be found in plants in two ways: free or bound form. The phenolic compounds which are in bound form are linked to cell wall components via ester bonds (Gupta \& De, 2017).

Novel extraction techniques include soxhlet extraction, ultrasound-assisted extraction, microwave-assisted extraction, supercritical fluid extraction, and accelerated solvent extraction. The advantages and disadvantages of these extraction techniques depend on physical and chemical conditions in the procedures. The main drawbacks of soxhlet extraction include the 
requirement of time, and solvent quantity, the potential for light, and thermal degradation of the extract. On the other hand, supercritical fluid extraction requires high costs with trained personnel to figure out the complex configuration of the system and monitor the extraction. Furthermore, supercritical carbon dioxide is not efficient for the extraction of more polar phenolic acids, while the ultrasound-assisted extraction method has many weaknesses such as large volume of solvent requirement and potential degradation of the extract by light and oxygen (Al Jitan et al., 2018).

When compared with the other techniques mentioned above, it has been shown that bound phenolic acids can also be extracted via MAE. Thus, MAE provides superiority for the studied parameters including TPC, TFC, FRAP, and MCC. The other advantages of MAE include rapid and inexpensive processes, short extraction time, the ability to conduct many extractions simultaneously, and less solvent requirement. The main drawback of MAE is the work of relatively low quantities.

In this study, total phenolic content, total flavonoid content, total antioxidant and metal chelating capacity of Sideritis montana ssp. montana were evaluated using classical and microwave-assisted extraction methods.

The concentrations of phenolic compounds obtained in Sideritis montana ssp. montana extract via MAE $(55 \mathrm{mg} / \mathrm{g})$ was found to be slightly higher than the conventional $(51 \mathrm{mg} / \mathrm{g})$ method (Figure 2). On the other hand, the phenolic compounds obtained via MAE were determined to be significantly low $(33 \mathrm{mg} / \mathrm{g}, p<0.05)$ at $85^{\circ} \mathrm{C}$ for the 20 minutes procedure, suggesting the total phenolic components to be degraded at high temperature. On the contrary, this situation was not observed at the same temperature for 8 and 14-minutes, suggesting that the degradation of phenolics is also related to the extraction time.

Figure 2. Total phenolic content of Sideritis montana ssp. montana extract. All values are expressed as $\mathrm{mg} \mathrm{GAE/g}$ dry plant samples.

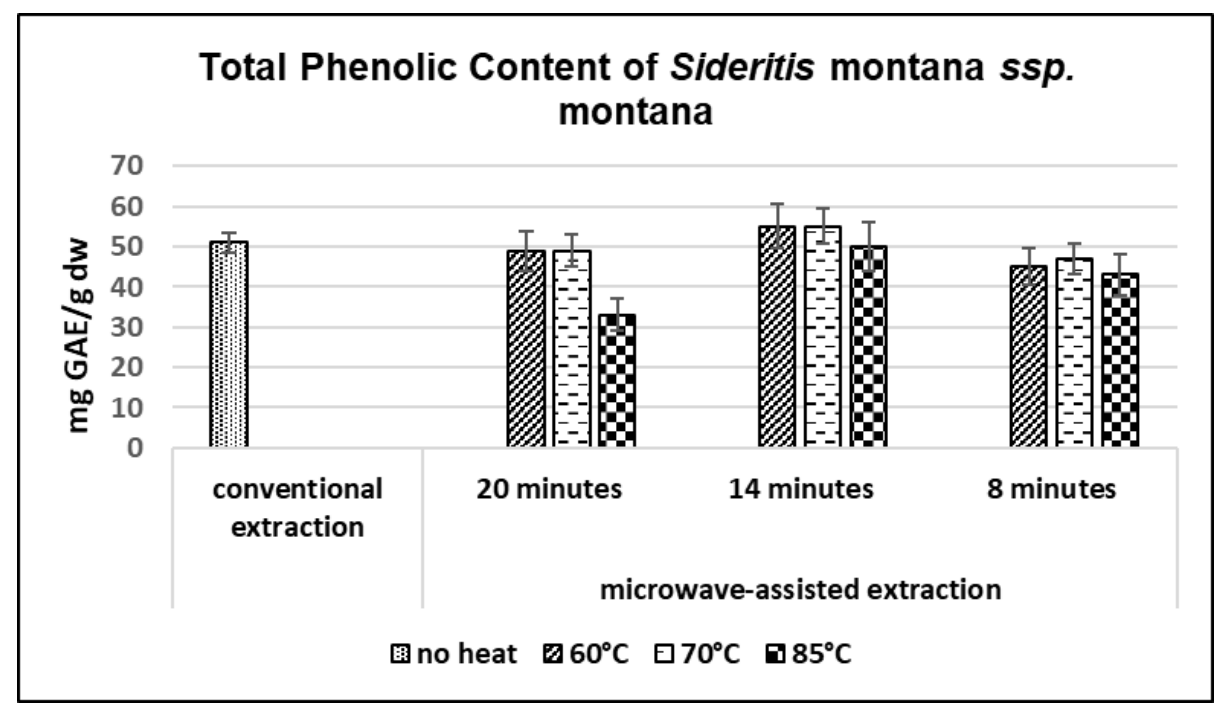

In the literature, a wide range of values (from 3.9 to $209 \mathrm{mg} / \mathrm{g}$ ) of TPC for Sideritis species (Table 2) were reported (Axiotis et al., 2020; Ertas \& Yener, 2020; Celep et al., 2019), attributable to the solvent type, extraction technique, time, and temperature, particularly boiling water. Higher TPC values were reported using infusion (boiling water) as shown in Table 2. The higher values for TFC were also found for the same samples shown in Table 2 supporting this explanation. 
Flavonoids are common and larger secondary metabolism compounds that occur naturally in plants. They are considered quality indicators of fruits and medical plants (Sammani et al., $2021)$. In this study, the concentration of flavonoids $(22 \mathrm{mg} / \mathrm{g})$ using MAE $\left(70^{\circ} \mathrm{C}, 8 \mathrm{~min}\right)$ was found to be significantly higher than $(p<0.05)$ the values $(16.3 \mathrm{mg} / \mathrm{g})$ obtained from the maceration (Figure 3). Many of the values obtained using MAE were found to be higher or close to the values obtained by the classical method.

Figure 3. Total flavonoid content of Sideritis montana ssp. montana extract. All values are expressed as $\mathrm{mg} \mathrm{QE} / \mathrm{g}$ dry plant samples.

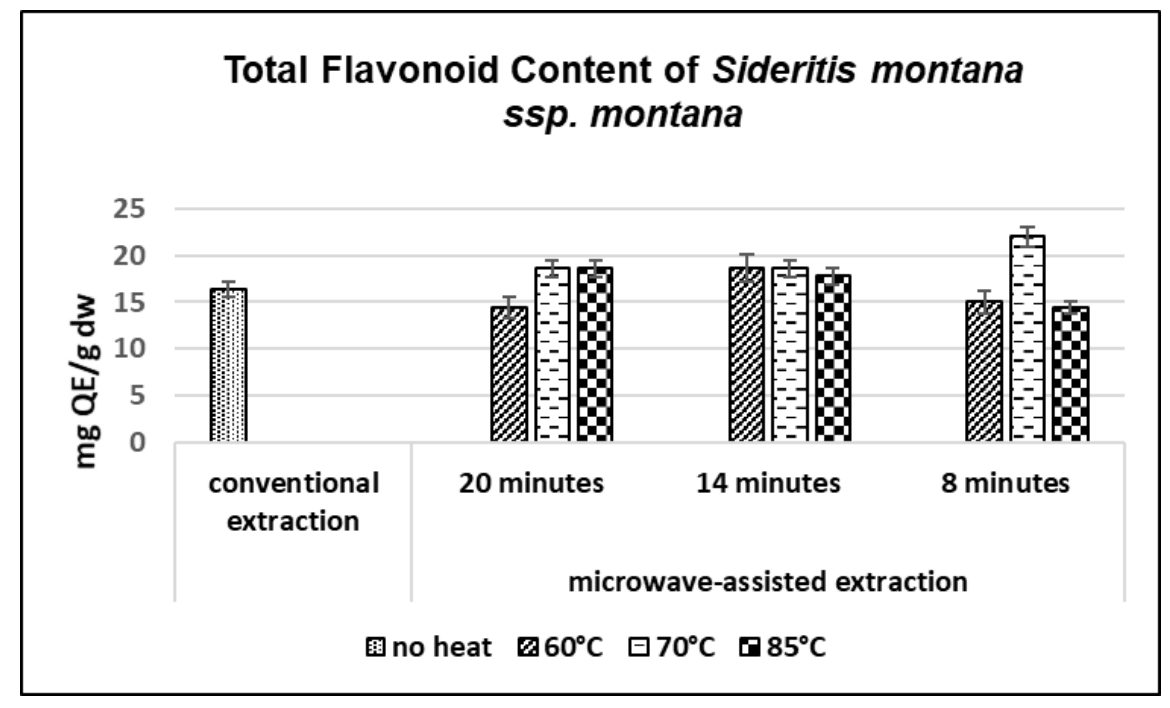

The TFC values reported in the literature were in wide range of 1.5-101 $\mathrm{mg}$ QE/g dw (Irakli et al., 2018; Kara et al., 2014; Sarikurkcu et al., 2020; Bardakci et al., 2020). As is shown in Table 2, these TPC values which are higher than our results were obtained from the infusion of the sample with boiled water. The other TPC values were lower than our results. Similarly, Table 2 shows that the TFC values in the literature which are higher than our TFC values were obtained using heat.

In this study, the antioxidant power of Sideritis montana extract obtained via MW-assisted extraction $(103 \mathrm{mg} / \mathrm{g})$ was obtained to be significantly higher $(p<0.05)$ than that of the extract obtained via the conventional method ( $93 \mathrm{mg} / \mathrm{g}$ ). In the MW-assisted extraction procedure, on the other hand, lower FRAP values were obtained at $60^{\circ} \mathrm{C}$ and $70^{\circ} \mathrm{C}$ for 20 minutes. The lower values at $60^{\circ} \mathrm{C}$ for 20 -minutes may be attributed to insufficient temperature. This situation implies that the molecules contributing to FRAP in mountain tea are significantly sensitive to temperature. Therefore, the maximum concentration was obtained at $85^{\circ} \mathrm{C}$ for 20 -minutes of extraction. Furthermore, at the 8-minutes of extraction, the highest degree of antioxidant power was found at $70^{\circ} \mathrm{C}$, suggesting that the antioxidant molecules contributing to FRAP assay are highly susceptible to extraction time and temperature (Figure 4).

The FRAP method measures the ability of antioxidants to perform as reducing agents. Potassium ferricyanide has been used as the ferric reagent in the FRAP assay. Transition metal ions are known to stimulate lipid oxidation via Fenton reaction and also by decomposing lipid hydroperoxides into more reactive peroxyl and alkoxyl radicals. By Fenton reaction, the ferrous ions produce $\bullet \mathrm{OH}$ radicals, which are highly reactive, and contribute appreciably to oxidative stress.

$$
\mathrm{Fe}^{2+}+\mathrm{H}_{2} \mathrm{O}_{2} \rightarrow \mathrm{Fe}^{3+}+\mathrm{OH}^{-}+\mathrm{OH}^{-} \quad \text { Fenton reaction }
$$


The resulting hydroxy radicals cause damage to proteins, carbohydrates, cellular lipids, and nucleic acids leading to cellular damage. Numerous metal ions such as $\mathrm{Cu}^{+}, \mathrm{Ti}^{3+}, \mathrm{Cr}^{2+}$, and $\mathrm{Co}^{2+}$ and their complexes in their lower oxidation states similarly react with $\mathrm{H}_{2} \mathrm{O}_{2}$ as $\mathrm{Fe}^{2+}$, and the mixtures of these metal ions with $\mathrm{H}_{2} \mathrm{O}_{2}$ are named "Fenton-like" reagents. The antioxidants, powerful metal chelators, can easily deactivate prooxidant metal ions and thus, prevent or retard metal ion-induced lipid oxidation. Phenolic compounds act as metal-chelators and scavengers of hydroxyl- and other radicals formed from iron-mediated Fenton reactions. In other words, polyphenols sacrificially reduce ROS/RNS, such as $\bullet \mathrm{OH}, \mathrm{O} 2 \bullet-$, NO , or OONO- after generation, preventing damage to biomolecules or formation of more reactive ROS. Typically, chlorogenic acid (CA) in Sideritis montana is known to be intercalated in Fenton reaction as follows (Zhou et al., 2019):

$$
\begin{aligned}
& \mathrm{CA}-\mathrm{Fe}(\mathrm{III})+\mathrm{H}_{2} \mathrm{O}_{2} \rightarrow \mathrm{CA}-\mathrm{Fe}(\mathrm{II})+\mathrm{HOO} .+\mathrm{H}^{+} \\
& \mathrm{CA}-\mathrm{Fe}(\mathrm{II})+\mathrm{H}_{2} \mathrm{O}_{2} \rightarrow \mathrm{CA}-\mathrm{Fe}(\mathrm{III})+\mathrm{OH}^{-}+. \mathrm{OH} \\
& \mathrm{Fe}^{3+}+\mathrm{CA} \rightarrow \mathrm{CA}-\mathrm{Fe}(\mathrm{III})(\text { chelate }) \\
& \mathrm{CA}-\mathrm{Fe}(\mathrm{III})+\mathrm{CA} \rightarrow \mathrm{CA}-\mathrm{Fe}(\mathrm{II})+[\mathrm{CA}]_{\mathrm{ox}}
\end{aligned}
$$

Figure 4. FRAP analysis of Sideritis montana ssp. montana extract. All values are expressed as mg QE/g dry plant samples.

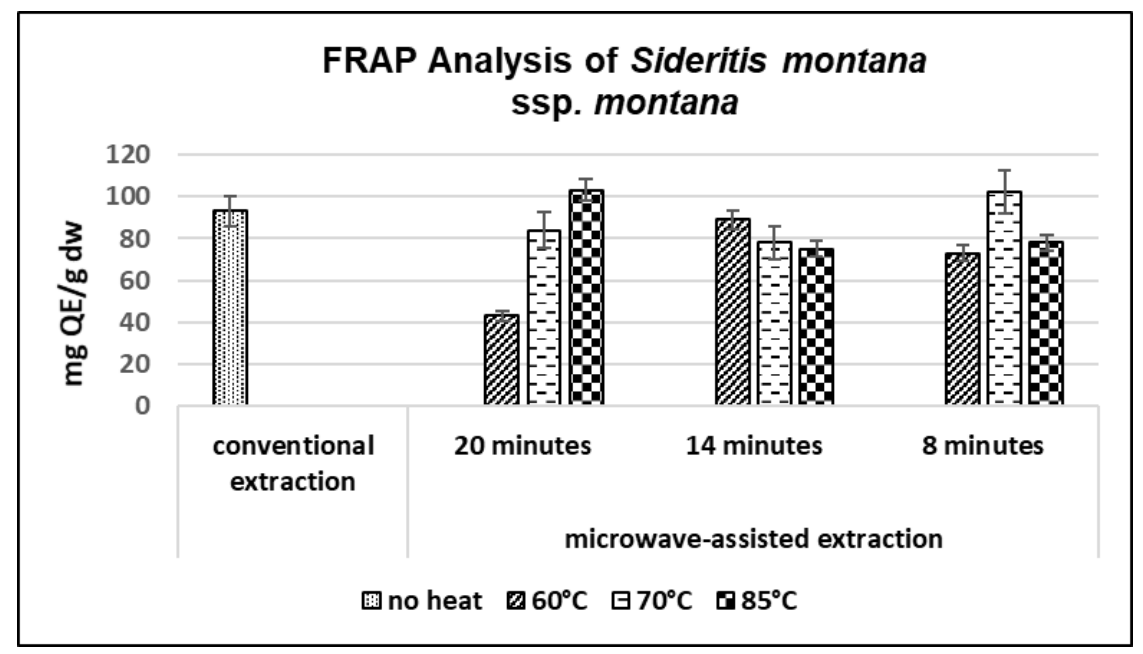

As seen above, CA representative of phenolic acids eliminates the production of more harmful radicals such as peroxyl and alkoxyl produced by metals. The antioxidant property of metal chelators is assessed when a complex is formed between the antioxidant and the metal, in such a way that metal ions can no longer act as an initiator of lipid oxidation. Polyphenols can chelate transition metal ions through their multiple $\mathrm{OH}$ groups and carbonyl moiety (Perron \& Brumaghim, 2009). Based on the feature and structure of CA, the major phenolic compound of Sideritis, the adjacent couple $\mathrm{OH}$ groups might chelate ferric iron ions to form a $\mathrm{Fe}^{3+}-\mathrm{CA}$ complex. Therefore, metal chelation capacity is also used as an indicator of antioxidant activity (Miah et al., 2020).

In this study, for the metal chelating capacity, the values obtained for 20-minutes for all extraction temperatures are higher or closer than the values found for the other extraction times using MAE. No significant differences were obtained with MAE for 20 -minutes at $85^{\circ} \mathrm{C}$ and the classical method (Figure 5). As a result, the molecules with metal chelating capacity in Sideritis montana ssp. montana extract was not found to be interconnected to the time and temperature conditions of the MAE method except for $60^{\circ} \mathrm{C}$ for $14 \mathrm{~min}$ and $60^{\circ} \mathrm{C}$ and $70^{\circ} \mathrm{C}$ for $80^{\circ} \mathrm{C}$. 


\section{CONCLUSION}

In this study, conventional and microwave-assisted extraction methods were compared in terms of obtaining TPC, TFC, FRAP, and MCC as well as extraction time and solvent quantity for mountain tea. The microwave-assisted extraction method was found to be superior to the classical method in Sideritis montana ssp. montana extraction. Phenolics and flavonoid compounds in mountain tea were found to be extremely sensitive to the temperature and extraction time in microwave-assisted extraction. The obtained results for classical extraction

Figure 5. The metal-chelating activity of Sideritis montana ssp. montana extract. All values are expressed as $\mathrm{mg} \mathrm{Fe}(\mathrm{II}) / \mathrm{g}$ dry plant samples.

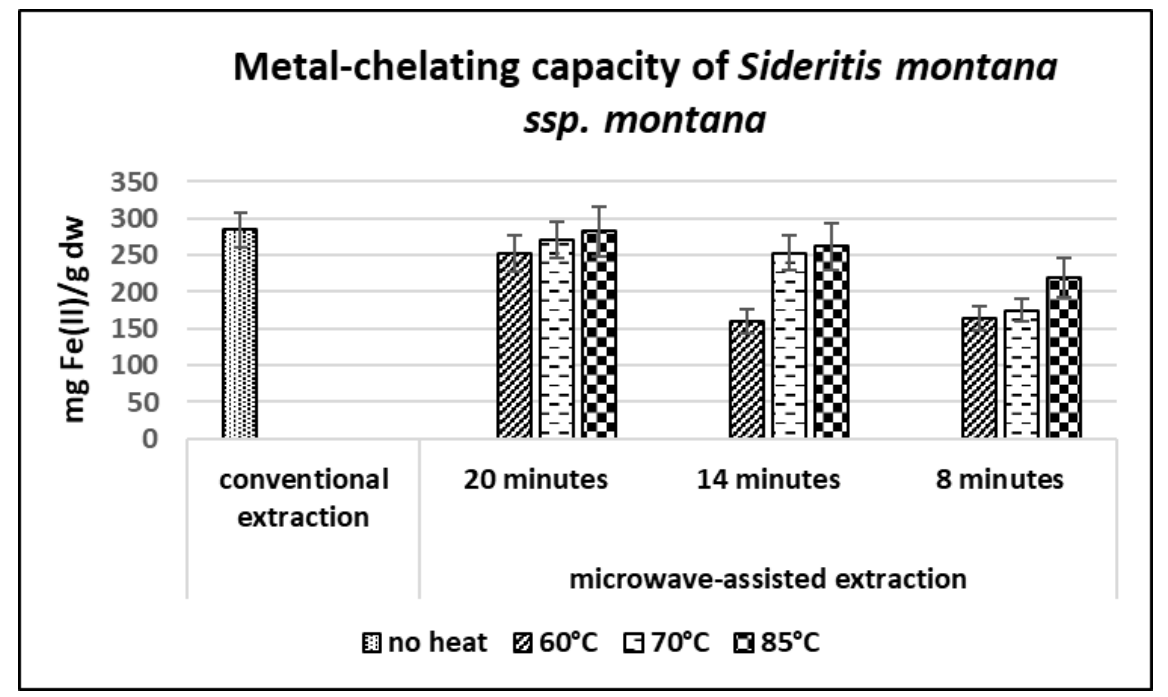

and MAE were found to be 40 and $43 \mathrm{mg} / \mathrm{g}$ for TPC, 12.4 and $22 \mathrm{mg} / \mathrm{g}$ for TFC, 37 and 49 $\mathrm{mg} / \mathrm{g}$ for FRAP, and 133 and $134 \mathrm{mg} / \mathrm{g}$ for MCC, respectively. In conclusion, microwaveassisted extraction of Sideritis montana ssp. montana has many advantages as its effectiveness, extraction time, and solvent quantity. Besides, Sideritis montana ssp. montana is suggested to be applied in the food industry as a natural antioxidant instead of synthetic ones to prevent health-damaging effects. 
Table 2. Literature values for the studied parameters of Sideritis species.

\begin{tabular}{|c|c|c|c|c|c|c|c|c|}
\hline Species & Ext type & Solvent & Ext time & $\begin{array}{c}\text { Samp/solv ratio } \\
(\mathrm{g} / \mathrm{mL})\end{array}$ & $\begin{array}{c}\text { TPC } \\
(\mathrm{mg} \mathrm{GAE} / \mathrm{g})\end{array}$ & $\begin{array}{c}\text { TFC } \\
(\mathrm{mg} \mathrm{QE} / \mathrm{g})\end{array}$ & $\begin{array}{c}\text { FRAP } \\
(\mathrm{mg} \mathrm{QE} / \mathrm{g})\end{array}$ & Reference \\
\hline S. scardica & INF & water & $\begin{array}{c}10 \mathrm{~m} \\
99.8^{\circ} \mathrm{C}\end{array}$ & $1: 100$ & 45.43 & $47.45 \mathrm{mg} \mathrm{CATE} / \mathrm{g}$ & - & (Irakli et al., 2018) \\
\hline S. condensate & INF & water & $5 \mathrm{~m} 60^{\circ} \mathrm{C}$ & $2.5: 60$ & 12.17 & - & - & (Kara et al., 2014) \\
\hline S. perfoliata & SOX & water & $5 \mathrm{~h}$ & $250 \mathrm{ml}$ & $52.18 \mathrm{mg} / \mathrm{g}$ ext & $29.13 \mathrm{mg} / \mathrm{g}$ ext & - & (Sarikurkcu et al., 2020) \\
\hline S. perfoliata & SOX & met & $5 \mathrm{~h}$ & $250 \mathrm{ml}$ & $41.64 \mathrm{mg} / \mathrm{g}$ ext & $40.90 \mathrm{mg} / \mathrm{g}$ ext & - & (Sarikurkcu et al., 2020) \\
\hline S. congesta & INF & water & ni & $2: 100$ & 209 & 101 & 1.37 & (Bardakci et al., 2020) \\
\hline S. sipylea & UAE & met & ni & $1: 40$ & 13.3 & - & - & (Axiotis et al., 2020) \\
\hline S. sipylea & UAE & $50 \%$ met & ni & $1: 40$ & 15.8 & - & - & (Axiotis et al., 2020) \\
\hline S. libanotica & MACE & met & $72 \mathrm{~h}$ & $10: 25$ & 6.5 & 2.4 & - & (Ertas \& Yener, 2020) \\
\hline S. libanotica & MACE & water & $72 \mathrm{~h}$ & $10: 25$ & 3.9 & 1.5 & - & (Ertas \& Yener, 2020) \\
\hline S. thirkei & MACE & met & $72 \mathrm{~h}$ & $10: 25$ & 8 & 2.9 & - & (Ertas \& Yener, 2020) \\
\hline S. thirkei & MACE & water & $72 \mathrm{~h}$ & $10: 25$ & 6.9 & 3.4 & - & (Ertas \& Yener, 2020) \\
\hline S. trojana & INF & water & $30 \mathrm{~m}$ & $2: 100$ & 85 & 36 & - & (Celep et al., 2019) \\
\hline S. trojana & MACE & $80 \%$ Eth & $30 \mathrm{~m} 45^{\circ} \mathrm{C}$ & $2: 100$ & 113 & 59 & - & (Celep et al., 2019) \\
\hline S. trojana & UAE & water & $45^{\circ} \mathrm{C}$ & $2: 100$ & 53 & 25 & - & (Celep et al., 2019) \\
\hline S. montana & MACE & met & $72 \mathrm{~h}$ & $10: 75$ & 51 & 16.3 & 93 & \multirow{2}{*}{ This study* } \\
\hline S. montana & MAE & $70 \%$ met & $20 \mathrm{~m}$ & $0.1: 8$ & 55 & 18.6 & 103 & \\
\hline
\end{tabular}

*RSD for this study ranges between 7-12\%. UAE: ultrasound-assisted extraction, MACE: maceration, MAE: microwave-assisted extraction, INF: infusion, SOX: soxhlet assisted extraction, met: methanol, m: minutes, h: hours, ni: no information 


\section{Acknowledgments}

I would like to thank Prof. Dr. Mehmet Yaman for his laboratory support.

\section{Declaration of Conflicting Interests and Ethics}

The author declare no conflict of interest. This research study complies with research and publishing ethics. The scientific and legal responsibility for manuscripts published in IJSM belongs to the author.

\section{Orcid}

Emel Akbaba (iD) https://orcid.org/0000-0003-4915-5153

\section{REFERENCES}

Al Jitan, S., Alkhoori, S. A., \& Yousef, L. F. (2018). Phenolic Acids From Plants: Extraction and Application to Human Health. In Studies in Natural Products Chemistry (1st ed., Vol. 58). Elsevier B.V. https://doi.org/10.1016/B978-0-444-64056-7.00013-1

Arruda, H. S., Neri-Numa, I. A., Kido, L. A., Maróstica Júnior, M. R., \& Pastore, G. M. (2020). Recent advances and possibilities for the use of plant phenolic compounds to manage ageingrelated diseases. Journal of Functional Foods, 75, 104203. https://doi.org/10.1016/j.jff.202 0.104203

Axiotis, E., Petrakis, E. A., Halabalaki, M., \& Mitakou, S. (2020). Phytochemical Profile and Biological Activity of Endemic Sideritis sipylea Boiss. in North Aegean Greek Islands. Molecules, 25(9). https://doi.org/10.3390/molecules25092022

Bardakci, H., Cevik, D., Barak, T. H., Gozet, T., Kan, Y., \& Kirmizibekmez, H. (2020). Secondary metabolites, phytochemical characterization and antioxidant activities of different extracts of Sideritis congesta P.H. Davis et Hub.-Mor. Biochemical Systematics and Ecology, 92, 104120. https://doi.org/10.1016/j.bse.2020.104120

Berker, K., Güçlü, K., Tor, I., Demirata, B., \& Apak, R. (2010). Total Antioxidant Capacity Assay Using Optimized Ferricyanide/Prussian Blue Method. Food Analytical Methods, 3, 154-168. https://doi.org/10.1007/s12161-009-9117-9

Bilginoğlu, E. (2017). The Investigation on Drug Yield and Some Quality Characteristics of Mountain Tea (Sideritis congesta) Cultivated in Turkey. International Journal of Secondary Metabolite, 4(1), 264-269. https://doi.org/10.21448/ijsm.372482

Celep, E., Seven, M., Akyüz, S., İnan, Y., \& Yesilada, E. (2019). Influence of extraction method on enzyme inhibition, phenolic profile and antioxidant capacity of Sideritis trojana Bornm. South African Journal of Botany, 121, 360-365. https://doi.org/10.1016/j.sajb.2018.11.026

Ceylan, Z., Meral, R., Kose, S., Sengor, G., Akinay, Y., Durmus, M., \& Ucar, Y. (2020). Characterized nano-size curcumin and rosemary oil for the limitation microbial spoilage of rainbow trout fillets. $L W T, 134,109965$. https://doi.org/10.1016/j.lwt.2020.109965

Chemat, F., Abert Vian, M., \& Zill-E-Huma. (2009). Microwave assisted - separations: Green chemistry in action. In Green Chemistry Research Trends.

Ertas, A., \& Yener, I. (2020). A comprehensive study on chemical and biological profiles of three herbal teas in Anatolia; rosmarinic and chlorogenic acids. South African Journal of Botany, 130, 274-281. https://doi.org/10.1016/j.sajb.2020.01.008

González-Burgos, E., Carretero, M. E., \& Gómez-Serranillos, M. P. (2011). Sideritis spp.: Uses, chemical composition and pharmacological activities - A review. Journal of Ethnopharmacology, 135(2), 209-225. https://doi.org/10.1016/j.jep.2011.03.014

Gupta, P., \& De, B. (2017). Differential responses of cell wall bound phenolic compounds in sensitive and tolerant varieties of rice in response to salinity. Plant Signaling \& Behavior, 12(10). https://doi.org/10.1080/15592324.2017.1379643

Irakli, M., Tsifodimou, K., Sarrou, E., \& Chatzopoulou, P. (2018). Optimization infusions 
conditions for improving phenolic content and antioxidant activity in Sideritis scardica tea using response surface methodology. Journal of Applied Research on Medicinal and Aromatic Plants, 8, 67-74. https://doi.org/10.1016/j.jarmap.2017.12.001

Kara, M., Sahin, H., Turumtay, H., Dinc, S., \& Gumuscu, A. (2014). The Phenolic Composition and Antioxidant Activity of Tea with different Parts of Sideritis condensate at Different Steeping Conditions. Journal of Food and Nutrition Research, 2(5), 258-262. https://doi.org/10.12691/jfnr-2-5-8

Magalhaes, L., Segundo, M., Reis, S., \& Lima, J. (2008). Methodological aspects about in vitro evaluation of antioxidant properties. Analytica Chimica Acta, 613, 1-19. https://doi.org/10.1016/j.aca.2008.02.047

Marchev, A. S., Vasileva, L. V, Amirova, K. M., Savova, M. S., Koycheva, I. K., BalchevaSivenova, Z. P., Vasileva, S. M., \& Georgiev, M. I. (2021). Rosmarinic acid - From bench to valuable applications in food industry. Trends in Food Science \& Technology. https://doi.org/10.1016/j.tifs.2021.03.015

Martelli, G., \& Giacomini, D. (2018). Antibacterial and antioxidant activities for natural and synthetic dual-active compounds. European Journal of Medicinal Chemistry, 158, 91-105. https://doi.org/10.1016/i.ejmech.2018.09.009

Miah, S., Fukiage, S., Begum, Z. A., Murakami, T., Mashio, A. S., Rahman, I. M. M., \& Hasegawa, H. (2020). A technique for the speciation analysis of metal-chelator complexes in aqueous matrices using ultra-performance liquid chromatography-quadrupole/time-offlight mass spectrometry. Journal of Chromatography A, 1630, 461528. https://doi.org/10.1016/j.chroma.2020.461528

Ognyanov, M., Remoroza, C. A., Schols, H. A., Petkova, N. T., \& Georgiev, Y. N. (2021). Structural study of a pectic polysaccharide fraction isolated from "mountain tea" (Sideritis scardica Griseb.). Carbohydrate Polymers, 260, 117798. https://doi.org/10.1016/j.carbpol. 2021.117798

Perron, N. R., \& Brumaghim, J. L. (2009). A review of the antioxidant mechanisms of polyphenol compounds related to iron binding. Cell Biochemistry and Biophysics, 53(2), 75 100. https://doi.org/10.1007/s12013-009-9043-x

Rodrigues, J. S., do Valle, C. P., Uchoa, A. F. J., Ramos, D. M., da Ponte, F. A. F., Rios, M. A. de S., de Queiroz Malveira, J., \& Pontes Silva Ricardo, N. M. (2020). Comparative study of synthetic and natural antioxidants on the oxidative stability of biodiesel from Tilapia oil. Renewable Energy, 156, 1100-1106. https://doi.org/10.1016/j.renene.2020.04.153

Sammani, M. S., Clavijo, S., \& Cerdà, V. (2021). Recent, advanced sample pretreatments and analytical methods for flavonoids determination in different samples. TrAC Trends in Analytical Chemistry, 138, 116220. https://doi.org/10.1016/j.trac.2021.116220

Sarikurkcu, C., Locatelli, M., Mocan, A., Zengin, G., \& Kirkan, B. (2020). Phenolic profile and bioactivities of Sideritis perfoliata L.: The plant, its most active extract, and its broad biological properties. Frontiers in Pharmacology, 10, 1642. https://doi.org/10.3389/fphar.2 $\underline{019.01642}$

Semiz, G., \& Özel, M. Z. (2017). Essential oil composition of endemic Sideritis leptoclada O. Schwarz\& P. H. Davis (Lamiaceae) from Turkey by using two-dimensional Gas Chromatography-Time-of-Flight Mass Spectrometry (GCxGC-TOF/MS). International Journal of Secondary Metabolite, 4(2), 137-137. https://doi.org/10.21448/ijsm.309535

Singleton, V. L., Orthofer, R., \& Lamuela-Raventós, R. M. B. T.-M. in E. (1999). Analysis of total phenols and other oxidation substrates and antioxidants by means of folin-ciocalteu reagent. Methods in Enzymology, 299, 178-184. https://doi.org/10.1016/S0076-6879(99)99 $017-1$

Xu, X., Liu, A., Hu, S., Ares, I., Martínez-Larrañaga, M.-R., Wang, X., Martínez, M., Anadón, A., \& Martínez, M.-A. (2021). Synthetic phenolic antioxidants: Metabolism, hazards and 
mechanism of action. Food Chemistry, 353, 129488. https://doi.org/10.1016/j.foodchem.20 $\underline{21.129488}$

Zhou, F., Jongberg, S., Zhao, M., Sun, W., \& Skibsted, L. H. (2019). Antioxidant efficiency and mechanisms of green tea, rosemary or maté extracts in porcine Longissimus dorsi subjected to iron-induced oxidative stress. Food Chemistry, 298, 125030. https://doi.org/10.1016/j.foodchem.2019.125030

Zyzelewicz, D., Kulbat-Warycha, K., Oracz, J., \& Zyelewicz, K. (2020). Polyphenols and Other Bioactive Compounds of Sideritis Plants and Their Potential Biological Activity. Molecules, 25(16). https://doi.org/10.3390/molecules 25163763 